\title{
Willingness to Take Travel-Related Health Risks-A Study among Finnish Tourists in Asia during the Avian Influenza Outbreak
}

\author{
A. R. Aro • A.-M. Vartti - M. Schreck • P. Turtiainen • \\ A. Uutela
}

Published online: 6 January 2009

(C) International Society of Behavioral Medicine 2008

\begin{abstract}
Background Health risk perception and behavior of tourists during epidemics is a challenge for behavioral medicine. Purpose The purpose was to analyze associations of psychosocial factors and willingness to take health risks on holiday and business trips.

Method Subjects (survey $n=338$ ) were Finnish tourists visiting South-East Asia during the avian influenza epidemic of 2004. On holidays, $13.8 \%$, and on business trips, $6.3 \%$ would take (rather) high risks, $14.1 \%$ reported having tendency to take health risks. Willingness to take health risks on both kinds of trips was lower among those +40 years old than those $<40$. Comparatively high risk-taking tendency and high perceived HIV risk were related to the increased willingness to take health risks on both kinds of trips.

Results On holidays, willingness to take health risks was related to trust in fate, and on business trips, this was also related to trust in God and less precautionary behavior of avoiding hand shaking, but also to higher estimation of other risks in life.

Conclusion Younger travelers and those on holidays are willing to take more health risks than those who are older or on business trips. Travel advice during epidemics could be differentially targeted to different age groups and to holiday and business travelers.
\end{abstract}

\footnotetext{
A. R. Aro $(\bowtie)$

Unit for Health Promotion Research, University of Southern

Denmark, Esbjerg,

Niels Bohrs Vej 9-10,

6700 Esbjerg, Denmark

e-mail: araro@health.sdu.dk

A.-M. Vartti $\cdot$ M. Schreck $\cdot$ P. Turtiainen $\cdot$ A. Uutela Department of Health Promotion and Chronic Disease Prevention, National Public Health Institute,

Helsinki, Finland
}

Keywords Avian flu $\cdot$ Travel $\cdot$ Risks taking $\cdot$ Risk perception

\section{Introduction}

Traveling to and from Southeast Asia - both in business and on holidays - is very common and is a rapidly growing field. Modern travel and transportation patterns pose a threat of spreading a potential human-transmissible influenza strain globally, providing a challenge not only to the health care systems but also to economies related to tourism, business, and goods transport-as was seen in the case of SARS. Experts are convinced that the potential influenza pandemic is best contained at the point of origin, in Southeast Asia [1].

Different kinds of travelers are exposed to different kinds of risk, and although there are very few studies on the theme, they seem to suggest that people perceive and take health risks differently when visiting, e.g., relatives and friends compared to being on business trips [2]. Holidays more often pose risks related to "letting it go," hedonistic life style, and looking for experiences, which increase the risk of infectious diseases such as HIV, food-related infections, and accidents [3-5]. Further, it is known that a minority of the travelers adhere to the health recommendations, e.g., on dietary restrictions [4]. On the other hand, it has been shown that travel clinic consultations can improve adherence, e.g., to malaria prophylaxis [6]. Awareness of, e. g., the avian influenza risk among the populations in the epidemic areas could also be improved [7].

In the present time of global travel and pandemic threat, there is an urgent need to learn about people's health risk perceptions and behaviors, as well as risk taking tendencies related to different kinds of travel. This is important for promoting appropriate precautionary behaviors, for plan- 
ning health promotion, and also for avoiding societal and economic disruption related to epidemic and pandemic threats. We know that risk perceptions reflect a broader set of cognitive and affective beliefs than simply estimations of the likelihood of an event [8], and that people's judgments are based on the availability bias and heuristic processing using easily available cues [9]. Research on perceptions and behaviors related to infectious diseases in general, and to pandemics in special, has not yet developed its theoretical basis in the same sense that it has been done in the area of chronic, lifestyle diseases. Leventhal's illness perception framework and self-regulation model [10-12], as well as psychosomatics health worry approach [13], and optimism theory to counter for risk perception bias [14] have mostly been used as theoretical approaches in this area. There is very little literature on determinants of health risk taking during travel, and no study to our knowledge has used validated psychological measures. The aim of this study was to analyze psychosocial factors related to the willingness to take health risks on holiday and business trips.

\section{Method}

The subjects were 338 Finnish tourists $(58 \%$ of 600 randomly drawn from the address database of Suntours) who had been to Thailand, Vietnam, China, Malaysia, and Singapore during the avian influenza epidemic in 2004. The age of the survey respondents varied from below 20 to over 70 years old, $62 \%$ were female, $29 \%$ had university education, and $79 \%$ were married. No reminders were possible due to anonymous responses.

Willingness to take travel-related health risks was asked separately for holiday trips and business trips using the question: "How high a travel-related health risk would you be willing to take? Please make a mark on the bar so that ' 1 ' means total unwillingness and ' 100 ' means total willingness to take a risk." The responses were categorized into four: $<25=$ no/very low (="very low"), $>25<50=$ rather low ("low"), $>50<75=$ rather high ("high"), and $>75=$ high "very high"). An open question "Please justify why you would be willing to take the risk you chose" was also asked. The instrument was largely based on the international SARS Psychosocial Research Consortium survey [15], with additional questions on risk perceptions: perceived personal and comparative risk of avian influenza, SARS, and infectious diseases in general; perceived risk of flu, other diseases, accidents, and other travel-related hazards; personal and comparative risk taking tendency; issues important in risk taking; perceived efficacy to prevent avian flu, SARS, and infectious diseases in general; and precautionary behaviors while on trip (for the items and the response categories, please see Table 1). Psychological scales included seven subscales of the Illness Attitudes Scales [13, 16]: fear of illness (general reliability 0.91 ) [17], worry about illness (0.92), effects of symptoms (0.93), concern about pain (0.87), fear of disease (0.92), fear of death (0.89), and health habits (0.79); Short-form Anxiety Inventory (0.84) [18]; Life Orientation Test (0.78) [19].

\section{Statistical Analyses}

Statistical analyses included descriptive statistics of frequencies and percentages and Chi square test for categorical variables and means and $t$ tests for continuous variables. Multiple forward stepwise logistic regression analysis was carried out separately for holidays and business trips to calculate odds ( $95 \%$ confidence intervals) for willingness to take travel-related health risks. When calculating odds ratios, willingness to take "very low" health risks was the reference category. Variables significantly $(p<0.05)$ associated with the risk-taking in the univariate logistic regression analysis were entered in a forward stepwise multiple logistic regression analysis in the order of descending magnitude of the coefficient/standard error, using $p$ value of $\leq 0.025$ as the criterion [20] for a difference between the deviances including/excluding the variable. The analyses were done by the SURVO soft ware [21]. $p$ smaller or equal to 0.05 was considered as statistically significant.

\section{Results}

On holiday trips, $62.3 \%$ of the tourists would take (no or) very low risk, and $14.7 \%$ would take (rather) high risk. On business trips, the respective figures were $70.4 \%$ and $8.4 \%$. Correlation between the willingness to take risks on holidays and business trips was 0.49 .

Over three quarters of the respondents saw their risk of avian influenza, and also of SARS, very low-on the same level as of HIV - whereas less than a quarter saw the risk of infectious diseases in general very low (Table 1). Examples of the attributions given for the willingness to take health risks on holiday trips included: "holiday is holiday, if something happens, can't help it"; and "risk should not ruin your holiday." Justifications comparing the attributions related to holiday and business trips included: "holiday trip has been paid from own pocket unlike the business trip"; "would not take risks on business trip under any circumstances, but would take risks on holiday trip because plans and preparations have been made in beforehand"; "on holidays you can make your own choices, on business trips the program dictates what you do." 
Table 1 Frequencies and distributions of the selected variables of perceived risk among Finnish tourists in Asia during the avian influenza outbreak, $n=338$

\begin{tabular}{|c|c|c|c|c|c|}
\hline Variable & Percent & Percent & Percent & Percent & Percent \\
\hline Perceived personal risk of & Very low & Low & Medium & High & Very high \\
\hline Avian flu & 72.6 & 21.9 & 2.9 & 0.3 & 0.6 \\
\hline SARS & 76.7 & 18.4 & 2.3 & 2.3 & 0.9 \\
\hline Mad cow disease & 81.0 & 12.7 & 2.3 & 1.2 & 1.2 \\
\hline Flu & 3.5 & 6.9 & 19.3 & 17.0 & 51.9 \\
\hline Infectious disease in general & 21.6 & 36.0 & 32.0 & 6.3 & 3.2 \\
\hline $\mathrm{HIV}$ & 78.4 & 15.0 & 1.7 & 0.0 & 2.0 \\
\hline Tuberculosis & 58.5 & 26.5 & 11.0 & 0.3 & 1.2 \\
\hline Heart attack & 19.6 & 29.4 & 41.2 & 6.6 & 1.2 \\
\hline Cancer & 18.4 & 26.8 & 42.9 & 5.2 & 4.9 \\
\hline Food poisoning & 11.0 & 27.1 & 38.0 & 13.8 & 7.8 \\
\hline Terrorist attack on trip & 55.9 & 31.1 & 9.8 & 0.3 & 1.2 \\
\hline Robbery on trip & 11.5 & 32.9 & 40.1 & 10.7 & 2.0 \\
\hline Robbery in the area of residence & 34.6 & 34.6 & 24.8 & 3.2 & 0.9 \\
\hline Comparative risk of $^{\mathrm{a}}$ & Much lower & Lower & Equal & Higher & Much higher \\
\hline Avian flu & 23.3 & 23.1 & 47.0 & 4.3 & 1.2 \\
\hline SARS & 24.5 & 22.2 & 47.0 & 4.3 & 1.2 \\
\hline Perceived efficacy to prevent infectious diseases & 0.3 & 5.5 & 42.7 & 40.3 & 9.5 \\
\hline Risk taking tendency & Absolutely yes & Sometimes & Generally not & Absolutely not & Cannot tell \\
\hline Personal health risk taking tendency & 2.0 & 12.1 & 59.7 & 22.2 & 3.2 \\
\hline Comparative health risk taking tendency ${ }^{\mathrm{a}}$ & $\begin{array}{l}\text { More often } \\
6.1\end{array}$ & $\begin{array}{c}\text { Equally often } \\
34.3\end{array}$ & $\begin{array}{c}\text { More seldom } \\
\quad 36.6\end{array}$ & $\begin{array}{c}\text { Cannot tell } \\
22.5\end{array}$ & \\
\hline Perceived control of health risks on trips & $\begin{array}{l}\text { Fully } \\
13.5\end{array}$ & $\begin{array}{c}\text { Somewhat } \\
81.8\end{array}$ & $\begin{array}{c}\text { Not really } \\
2.9\end{array}$ & $\begin{array}{c}\text { Not at all } \\
0.9\end{array}$ & \\
\hline Willingness to take health risks on holidays & $\begin{array}{c}\text { Very low } \\
57.3\end{array}$ & $\begin{array}{l}\text { Low } \\
21.0\end{array}$ & $\begin{array}{l}\text { High } \\
8.9\end{array}$ & $\begin{array}{c}\text { Very high } \\
4.9\end{array}$ & \\
\hline Willingness to health risks on business trips & $\begin{array}{c}\text { Very low } \\
51.0\end{array}$ & $\begin{array}{l}\text { Low } \\
15.3\end{array}$ & $\begin{array}{l}\text { High } \\
4.0\end{array}$ & $\begin{array}{c}\text { Very high } \\
2.3\end{array}$ & \\
\hline
\end{tabular}

The percentages do not round up to 100 due to missing values, which range $0.9-2.9 \%$ in different variables, except for willingness to take health risks on holidays $(7.8 \%)$ and on business trips $(27.4 \%)$.

${ }^{a}$ Perceived risk compared to the same gender, age, and country of residence

Fourteen percent considered themselves having a tendency to take health risks, $6.1 \%$ more often than their peers (Table 1). In the multivariate analysis, the willingness to take health risks on holidays was lower among those older than 40 years old compared to those $<40$. Comparatively higher risk taking tendency and higher perceived HIV risk were related to the increased willingness to take health risks on both kinds of trips. Willingness to take health risks (especially) on holidays was also related to trust in fate, and on business trips also to trust in God, and to less precautionary behaviors indicated by lower avoidance of hand shaking while traveling in the epidemic area, but also to more rational estimates of other risks in life such as risk of robbery in the area of residence (Table 2). None of the psychological scales used appeared in the final model of the multivariate analysis as being significantly associated with the willingness to take health risks while traveling.

\section{Discussion}

This study among Finnish tourists who had been in Asia during the avian influenza outbreak showed that the strongest correlates of the willingness to take health risks on holiday and business trips were the same: younger age, perceived higher HIV risk, and higher perceived comparative health risk-taking tendency. The quotes from the answers to the open question showed that holidays inherently have a hedonistic function: people want to relax and they are ready to loosen control while being in unfamiliar circumstances and free from everyday life. The quotes about holidays being planned for and paid out of their own pocket implied that cancellations or changes were not (so easily) an option even if there were health risks. On the other hand, willingness to take health risks on business trips was more clearly related to rational risk evaluation of other risks in life. 
Table 2 Multivariate forward stepwise logistic regression analysis of factors increasing the willingness to take health risks on (a) holidays and (b) business trips, among Finnish tourists $(n=338)$ in Asia during the avian influenza outbreak

\begin{tabular}{|c|c|c|c|c|}
\hline Variable & Reference & $p$ Value & Odds ratio & $95 \% \mathrm{CI}$ \\
\hline \multicolumn{5}{|l|}{ (a) Holidays } \\
\hline Age & $<40$ & & 1.00 & \\
\hline $40-49$ & & 0.007 & 0.34 & $0.16-0.75$ \\
\hline $50-59$ & & 0.029 & 0.49 & $0.26-0.93$ \\
\hline$>59$ & & 0.003 & 0.28 & $0.12-0.65$ \\
\hline HIV risk perceived & Low/negligible & & 1.00 & \\
\hline Higher & & 0.013 & 2.16 & $1.18-3.97$ \\
\hline Comparative risk taking tendency & Lower/same as others & & 1.00 & \\
\hline Higher & & $<0.001$ & 2.63 & $1.59-4.34$ \\
\hline Getting experiences & No & & 1.00 & \\
\hline Yes & & 0.205 & 1.56 & $0.78-3.13$ \\
\hline Trust in fate & No & & 1.00 & \\
\hline Yes & & 0.006 & 2.47 & $1.30-4.71$ \\
\hline Avoiding hand shaking & No & & 1.00 & \\
\hline Yes & & 0.221 & 0.60 & $0.27-1.35$ \\
\hline Avoiding certain food & No & & 1.00 & \\
\hline Yes & & 0.132 & 0.67 & $0.41-1.12$ \\
\hline \multicolumn{5}{|l|}{ (b) Business trips } \\
\hline Age & $<40$ & & 1.00 & \\
\hline $40-49$ & & 0.068 & 0.43 & $0.18-1.07$ \\
\hline $50-59$ & & 0.488 & 0.78 & $0.38-1.58$ \\
\hline$>59$ & & 0.008 & 0.23 & $0.08-0.68$ \\
\hline Perceived HIV risk & Low/negligible & & 1.00 & \\
\hline Higher & & 0.178 & 1.60 & $0.81-3.18$ \\
\hline Comparative risk taking tendency & Lower/=others & & 1.00 & \\
\hline Higher & & 0.003 & 2.84 & $1.59-5.09$ \\
\hline Trust in fate & No & & 1.00 & \\
\hline Yes & & 0.170 & 1.67 & $0.80-3.47$ \\
\hline Avoiding hand shaking & No & & 1.00 & \\
\hline Yes & & 0.007 & 0.17 & $0.05-0.61$ \\
\hline Perceived risk of robbery in area of residence & Very low & & 1.00 & \\
\hline Higher & & 0.031 & 2.05 & $1.07-3.94$ \\
\hline Perceived avian flu risk, others & Very low & & 1.00 & \\
\hline Higher & & 0.077 & 1.79 & $0.94-3.41$ \\
\hline Statistical probability important in risk taking & No & & 1.00 & \\
\hline Yes & & 0.109 & 1.60 & $0.90-2.86$ \\
\hline Trust in God & No & & 1.00 & \\
\hline Yes & & 0.017 & 3.09 & $1.23-7.79$ \\
\hline
\end{tabular}

For each categorical variable, odds for willingness to take health risks in a given category were calculated relative to the reference category. CI confidence intervals

Interestingly, the precautionary behavior of avoiding hand shaking while traveling in the epidemic area was related to decreased willingness to take health risks on both kinds of trips, but more robustly on business trips, whereas avoiding certain foods was related (although confidence intervals included one) to decreased willingness to take health risks only on holiday trips. Holiday makers eat in more various surroundings, move around more, and have assumingly more time to interact with the local population than those on business trips. These partly different indicators of precautionary travel behaviors during the avian influenza epidemic point to the need for tailored risk communication especially during outbreaks for different groups of travelers.

It is surprising that there are no previous studies comparing risk perceptions and behaviors on holidays vs business trips, although traveling for both purposes is very common and is rapidly increasing. However, one study [2] has shown that those visiting family abroad differ from those on business trips in poorer adherence to some prophylactic measures, probably due to (false) reassurance of lower risks when staying with people they know. Studies 
on risk perception related to infectious diseases such as SARS and avian influenza and their relation with precautionary behaviors in general, have shown great variation between countries both in perceptions and behaviors [7, 22].

The results about the younger age and the willingness to take health risks especially on holidays are in line with the studies showing that younger people especially take more health risks while traveling, e.g., by neglecting protecting hygienic measures, and behave in general in a more hedonistic way than they normally do [3-5].

The fact that perceived HIV risk was strongly related to the willingness to take health risks on both kinds of trips emphasizes two things: first, the role of volitional control of the risks, and second, the conscious risk taking. A review [23] suggested that preventive advice should be given to all people going on holiday but particularly those going to the developing world, and young people especially should be encouraged to attend sexual screens after their holidays. In our study, none of the psychological scales included were related to the willingness to take health risks in the multivariate analysis. On the other hand, respondents' own perceptions of having a comparatively high risk-taking tendency was related to the willingness to take risks. Maybe estimating personal health risks is more related to subjective risk factor theories than to general psychological tendency or constructs [24].

Our study has some limitations. First, the subjects were tourists who had been on a holiday trip in Asia during the avian influenza epidemic. This might influence the results in several ways. First, the subjects might be a somewhat selected group of risk takers since they chose to travel to the region where avian influenza epidemic was active. However, no travel restrictions were in place. Second, the respondents were tourists. This is reflected in the $27 \%$ of missing values in the measure of willingness to take health risks on business trips - this option simply was not salient for one quarter of the respondents. Third, due to the anonymous responses and no reminder, the response rate was modest by the Finnish standards. The survey was also retrospective in questioning behaviors during the trip since it was sent at the end of 2004 and the trips had been made in the course of 2004. On the other hand, avian influenza, differently from SARS, was not contained in a few months, thus making that disease a salient threat still later in the year.

\section{Conclusion}

Younger travelers and those on holidays are willing to take more travel-related health risks than older and people on business trips. Travel advice with special precautionary measures during epidemics could be differentially targeted to different age groups and holiday and business travelers.

Acknowledgement M Lindholm Eriksen did the final technical editing of the text and tables.

\section{References}

1. Ferguson NM, Cummings DA, Cauchemez S, Fraser C, Riley S, Meeyai A, et al. Strategies for containing an emerging influenza pandemic in Southeast Asia. Nature 2005;437:209-14.

2. Van Herck K, Van Damme P, Castelli F, Zuckerman J, Nothdurft $\mathrm{H}$, Dahlgren $\mathrm{AL}$, et al. Knowledge, attitudes and practices in travel-related infectious diseases: the European airport survey. J Travel Med. 2004;11:3-8.

3. Dahl UR, Petersen FC. Health risks of overseas travel: ignorance and complacency prevail about infectious diseases. Brit Med J. 2004;328:464.

4. Rack J, Wichmann O, Kamara B, Gunther M, Cramer J, Schonfeld C, et al. Risk and spectrum of diseases in travelers to popular tourist destinations. J Travel Med. 2005;12:248-53.

5. Thomas M. What happens in Tenerife stays in Tenerife': Understanding women's sexual behaviour on holiday. Cult Health Sex. 2005;7:571-84.

6. Farquharson L, Noble LM, Barker C, Behrens RH. Health beliefs and communication in the travel clinic consultation as predictors of adherence to malaria chemoprophylaxis. Br J Health Psychol. 2004;9:201-17.

7. Fielding R, Lam WW, Ho EY, Lam TH, Hedley AJ, Leung GM. Avian influenza risk perception, Hong Kong. Emerg Infect Dis. 2005;11:677-82.

8. Rothman AJ, Kiviniemi MT. Treating people with information: an analysis and review of approaches to communicating health risk information. J Nat Cancer Inst. 1999;25:44-51.

9. Tversky A, Kahneman D. Judgment under uncertainty: heuristics and biases. Science 1974;185:1124-31.

10. Leventhal H, Benyamini Y, Brownlee S, Diefenbach M, Leventhal E, Patric-Miller L, et al. Illness representations: theoretical foundations. In: Petrie KJ, Weinman JA, editors. Perceptions of health and illness: current research and applications. London: Harwood; 1997. p. 19-45.

11. Leventhal H, Diefenbach M. The active side of illness. In: Skelton J, Croyle R, editors. Mental representation of health and illness. New York: Springer; 1991. p. 247-72.

12. Leventhal H, Diefenbach M, Leventhal E. Illness cognition: Using common sense to understand treatment adherence and affect cognition interactions. Cogn Ther Res. 1992;16:143-63.

13. Kellner R. Abridged manual of the illness attitude scales. Albuquerque: Department of Psychiatry, School of Medicine, University of New Mexico; 1998.

14. Weinstein N, Lyon J. Mindset, optimistic bias about personal risk and health-protective behaviour. Br J Health Psychol. 1994;4:289-300.

15. Brug J, Aro AR, Oenema A, de Zwart O, Richardus JH, Bishop GD. SARS risk perception, knowledge, precautions, and information sources, the Netherlands. Emerg Infect Dis. 2004;10:1486-9.

16. Aro AR, De Koning HJ, Absetz P, Schreck M. Psychosocial predictors of first attendance for organized mammography screening. J Med Screen. 1999;6:82-8.

17. Tarkkonen L, Vehkalahti K. Measurement errors in multivariate measurement scales. J Multivar Anal. 2005;96:172-89.

18. Marteau TM, Bekker H. The development of a six-item shortform of the state scale of the Spielberger State-Trait Anxiety Inventory (STAI). Brit J Clin Psychol. 1992;31:301-6. 
19. Scheier MF, Carver CS. Effects of optimism on psychological and physical wellbeing: Theoretical overview and empirical update. Cog Ther Res. 1992;16:201-28.

20. Mickey J, Greenland S. A study of the impact of confounder-selection criteria on effect estimation. Am J Epidemiol. 1989;129:125-37.

21. Mustonen S. Survo. An integrated environment for statistical computing and related areas. Helsinki: Survo Systems [Computer software]. http://www.survo.fi/english/ (1992).
22. de Zwart O, Veldhuijzen IK, Elam G, Aro AR, Abraham T, Bishop GD, et al. Avian influenza risk perception, Europe and Asia. Emerg Infect Dis. 2007;13:290-3.

23. Rogstad KE. Sex, sun, sea, and STIs: sexually transmitted infections acquired on holiday. Brit Med J. 2004;329:214-7.

24. Hahn A, Renner B. Perception of health risks: how smoker status affects defensive optimism. Anxiety Stress Coping. 1998;11:93. 